Article

\title{
Effect of Meltable Triazine-DOPO Additive on Rheological, Mechanical, and Flammability Properties of PA6
}

\author{
Irina Butnaru ${ }^{1,2}$, María P. Fernández-Ronco ${ }^{2}$, Justyna Czech-Polak ${ }^{3}$, Maciej Heneczkowski ${ }^{3}$, \\ Maria Bruma ${ }^{1}$ and Sabyasachi Gaan ${ }^{2, *}$ \\ ${ }^{1}$ Polycondensation Department, "Petru Poni” Institute of Macromolecular Chemistry, \\ Aleea Grigore Ghica Voda, 41A, Iasi, 700487, Romania; E-Mails: ibacosca@ icmpp.ro (I.B.); \\ mbruma@icmpp.ro (M.B.) \\ ${ }^{2}$ Laboratory for Advanced Fibers, Empa, Swiss Federal Laboratories for Materials Science and \\ Technology, Lerchenfeldstrasse 5, 9014 St. Gallen, Switzerland; E-Mail: Maria.Fernandez@empa.ch \\ ${ }^{3}$ Department of Technology and Materials Chemistry, Rzeszow University of Technology, \\ Powstancow Warszawy 6, 35-959 Rzeszow, Poland; E-Mails: czech_polak@interia.pl (J.C.-P.); \\ mhen@prz.edu.pl (M.H.) \\ * Author to whom correspondence should be addressed; E-Mail: sabyasachi.gaan@empa.ch; \\ Tel.: +41-5-8765-7611; Fax: +41-5-8765-7862.
}

Academic Editor: Alexander Morgan

Received: 2 July 2015 / Accepted: 11 August 2015 / Published: 17 August 2015

\begin{abstract}
Through a straightforward approach, a new meltable, halogen-free, nitrogen-phosphorus-based flame retardant (FR), 6-(2-(4,6-diamino-1,3,5-triazin-2-yl)ethyl) dibenzo[c,e][1,2] oxaphosphinine 6-oxide (DTE-DOPO) was synthesized and incorporated in polyamide 6 (PA6). It was proved that a very low phosphorus content of $1.46 \mathrm{wt} \%$ for DTE-DOPO additive improved the flame retardancy of PA6, leading to a non-flammable material. The performance of the new additive was compared to that of the commercially-available Exolit ${ }^{\circledR}$ OP 1230. The PA6 formulations were evaluated by measuring the rheological, mechanical, and flammability behavior. Using compounding by melt extrusion, $17 \mathrm{wt} \%$ additives was introduced into PA6 matrix and the corresponding formulations were characterized. The results evidenced a higher homogeneity of DTE-DOPO with PA6, a high thermal stability with a catalyzing decomposition effect on PA6 caused by the presence of the new developed FR, enhanced elasticity for the PA6/DTE-DOPO formulation and a V0 rating for both formulations. Thermal and fire analysis indicated a primary gas-phase activity, combined with a complete suppression of the self-sustained burning for the PA6/DTE-DOPO formulation.
\end{abstract}


Keywords: Polyamide 6; halogen-free flame retardant; flame retardancy; PCFC; UL-94 test; DIP-MS

\section{Introduction}

Polyamide 6 (PA6) is one of the most important engineering plastics which has been widely used in advanced technologies including electronic industries, telecommunications, and automotive production. Despite its attractive properties, the use of PA6 is still restricted in many applications where fire safety is important because of its inadequate flame retardance and severe flammable dripping [1]. As a result, the improvement of the flame retardance of PA6 has gained much attention in the last decades.

In the past, the flame retardant (FR) market was dominated by the highly-efficient halogenated compounds. However, the formation of highly toxic compounds during their thermal decomposition, such as halogenated dioxins and furans, has restricted their use in the recent years [2]. For example, established halogenated FRs belonging to the polybrominated diphenyl ethers have been already banned in the European Union (EU), China, and several U.S. states, due to their persistence, long-range transport, and potential toxicity to wildlife and human populations [3]. In this context, there is an increasing demand for the development of non-halogenated FRs which is stimulated by the environmental concerns aroused by their halogenated analogues [4].

Within the new non-halogenated FRs, researchers have proposed different types including red phosphorus [5], magnesium hydroxide [6,7], boron [8], organoclay nanocomposites [9,10], glass-fiber [11,12], silicon [13], multiwall carbon nanotubes composites [14-16], carbon fiber [17], and melamine-based products [18-20] in various combinations. Phosphorus-based FRs are among the most efficient and versatile flame retardants, and most of them can act through a combination of vapor- (inhibition of active species in gas phase) and condensed-phase reactions (promotion of the polymer carbonization and char formation) [21,22]. A solution for obtaining sustainable, but also efficient FRs is provided by compounds containing phosphorus $(\mathrm{P})$ and nitrogen $(\mathrm{N})$ as possible synergists [23,24]. The most important nitrogen-containing flame retardants are melamine and its derivatives. Melamine sublimates at approximately $350{ }^{\circ} \mathrm{C}$ rather than going through a traditional melting phase change, absorbing a significant amount of heat $(1965 \mathrm{~kJ} / \mathrm{mol})$ and, thus, acting as a heat sink in case of fire. Vaporized melamine also acts as an inert gas and dilutes the oxygen and fuel gases present at the point of combustion. Melamine also destabilizes PA6 and increases the dripping behavior of the polymer; therefore, the fuel source is removed from the combustion zone [22]. Concerning the phosphorous-containing flame retardants, 9,10-dihydro-9-oxa-10-phosphaphenanthrene-10-oxide (DOPO) and its derivatives could be an attractive FR solution for PA6 due to their relatively higher thermal stability [25-28]. DOPO and its derivatives are known to predominantly act by a gas-phase mechanism, through the formation of PO radicals, which might also be assisted by a condensed-phase activity via the incorporation of specific functionalities at the DOPO moiety [25,29]. Despite the promising performance of these non-halogenated FRs, there are still some problems which need to be overcome. One source of difficulty relates to their application in polyamides, i.e., the use of high processing temperatures, greater than $240{ }^{\circ} \mathrm{C}$ in extrusion or injection molding operations [30]. 
Apart from their thermal stability and migration issues, key factors such as compatibility, effect on mechanical and electrical performance, toxicity, cost-effectiveness, ability to cause corrosion, color stability, recyclability, as well as sustainability in general, need to be kept in mind while developing new non-halogenated FR for polyamide 6 . The recent trend of miniaturization of polyamide based electrical and electronic components provide the additional challenge to develop thin-walled $(<7 \mathrm{~mm})$ parts which have adequate flame retardant properties, while retaining adequate mechanical properties. Hence, the task to make or prepare flame retardant PA6 is quite challenging.

The main aim of this work has been to develop a new phosphorus-nitrogen-containing halogen-free flame-retardant for PA6 which allows maintaining the excellent mechanical properties, high thermal stability, and good processability of the polymer while improving, at the same time, its flame resistance to a V0 rating in the UL 94 test. Therefore, a meltable triazine-DOPO based FR: 6-(2-(4,6-diamino-1,3,5-triazin-2-yl)ethyl)dibenzo[c,e][1,2] oxaphosphinine 6-oxide (DTE-DOPO) has been synthesized. The flame-retardant efficiency of DTE-DOPO has been assessed in comparison with a non-meltable, commercially-available FR additive Exolit ${ }^{\circledR}$ OP 1230 (Clariant GmbH, Muttenz, Switzerland). To evaluate the influence of their incorporation in a PA6 matrix, two formulations containing $17 \mathrm{wt} \%$ additives each have been obtained using compounding by melt extrusion, and their mechanical, thermal, rheological, and flammability properties have been evaluated and compared with neat PA6.

\section{Experimental Section}

\subsection{Materials}

9,10-Dihydro-9-oxa-10-phosphaphenantrene-10-oxide (DOPO) was purchased from Krems Chemie Chemical Services AG, Krems, Austria. 2-Vinyl-4,6-diamino-1,3,5-triazine was purchased from TCI Europe, Antwerp, Belgium. Polyamide 6 (Natur A26) was provided by EMS-CHEMIE AG, Domat/EMS, Switzerland. The aluminium diethylphosphinate (Exolit ${ }^{\circledR}$ OP 1230) was supplied by Clariant GmbH, Muttenz, Switzerland. 1,8-Diazabicyclo[5.4.0]undec-7-ene (DBU) and toluene were purchased from Sigma Aldrich, Buchs SG, Switzerland. All chemicals were used in the synthesis as received, without any further purification.

\subsection{Synthesis of 6-(2-(4,6-Diamino-1,3,5-triazin-2-yl)ethyl)dibenzo[c,e][1,2]oxaphosphinine-6-oxide} (DTE-DOPO)

6-(2-(4,6-Diamino-1,3,5-triazin-2-yl)ethyl)dibenzo[c,e][1,2]oxaphosphinine 6-oxide (DTE-DOPO) was synthesized by an addition reaction of DOPO to 2-vinyl-4,6-diamino-1,3,5-triazine in the presence of DBU as catalyst and toluene as solvent. In a $5 \mathrm{~L}$ glass reactor equipped with a thermostat, mechanical stirrer, thermometer, inert gas inlet and outlet, $226.8 \mathrm{~g}(1.05 \mathrm{~mol}) \mathrm{DOPO}$ was added in portions at $80{ }^{\circ} \mathrm{C}$ to a solution of $137 \mathrm{~g}(1 \mathrm{~mol})$ 2-vinyl-4,6-diamino-1,3,5-triazine, $20 \mathrm{~mL}(0.1 \mathrm{~mol}) \mathrm{DBU}$ and $1.4 \mathrm{~L}$ toluene. After the addition was completed, the reaction mixture was refluxed and stirred for a further $17 \mathrm{~h}$. The reaction mixture was filtered and the solid was washed with $0.8 \mathrm{~L}$ of hot ethanol, filtered, and dried under vacuum at $80{ }^{\circ} \mathrm{C}$ for $24 \mathrm{~h}$ to obtain $325 \mathrm{~g}$ of white solid powder in a yield of $93 \%$ (Scheme 1). m.p. $=257^{\circ} \mathrm{C} .{ }^{1} \mathrm{H}$ NMR $\left(\mathrm{DMSO}_{-} \mathrm{d}_{6}, 400.13 \mathrm{MHz}\right) \delta(\mathrm{ppm}): 6.58\left(\mathrm{~s}, 4 \mathrm{H}, \mathrm{NH}_{2}\right), 7.23-7.32$ 
(m, 2H, Ar-H), 7.42-7.46 (t, 1H, Ar-H), 7.56-7.61 (t, 1H, Ar-H), 7.57-7.79 (t, 1H, Ar-H), 7.88-7.93 $(\mathrm{t}, 1 \mathrm{H}, \mathrm{Ar}-\mathrm{H}), 8.14-8.21(\mathrm{~m}, 2 \mathrm{H}, \mathrm{Ar}-\mathrm{H}) .{ }^{13} \mathrm{C}$ NMR (DMSO-d 6 , 100.61 MHz) $\delta(\mathrm{ppm}): 24.5,25.5,30$, $119.9,120.3,121.7,121.8,123.7,124.3,124.4,124.8,124.9,125.7,128.6,128.7,129.7,129.9,130.8$, 133.4, 134.6, 134.7, 148.6, 148.7, 166.8, 175.5. ${ }^{31} \mathrm{P}$ NMR (DMSO-d 6 , $\left.161.96 \mathrm{MHz}\right) \delta(\mathrm{ppm}): 37.68$. FTIR (KBr, powder, $\left.\mathrm{cm}^{-1}\right)$ : 3298, $3101(\mathrm{~N}-\mathrm{H}), 3060(\mathrm{Ar}-\mathrm{H}), 1649(\mathrm{C}=\mathrm{C}), 1538$ (triazine ring), 1437 $\left(\mathrm{P}-\mathrm{CH}_{2}\right), 1184(\mathrm{P}=\mathrm{O}), 910(\mathrm{P}-\mathrm{O}-\mathrm{Ph})$. High-resolution mass spectrometry (HRMS) $(\mathrm{m} / \mathrm{z}):[\mathrm{MH}]^{+}$calcd for $\mathrm{C}_{17} \mathrm{H}_{16} \mathrm{~N}_{5} \mathrm{O}_{2} \mathrm{P}$ 354.1114. Found: 354.1114 .

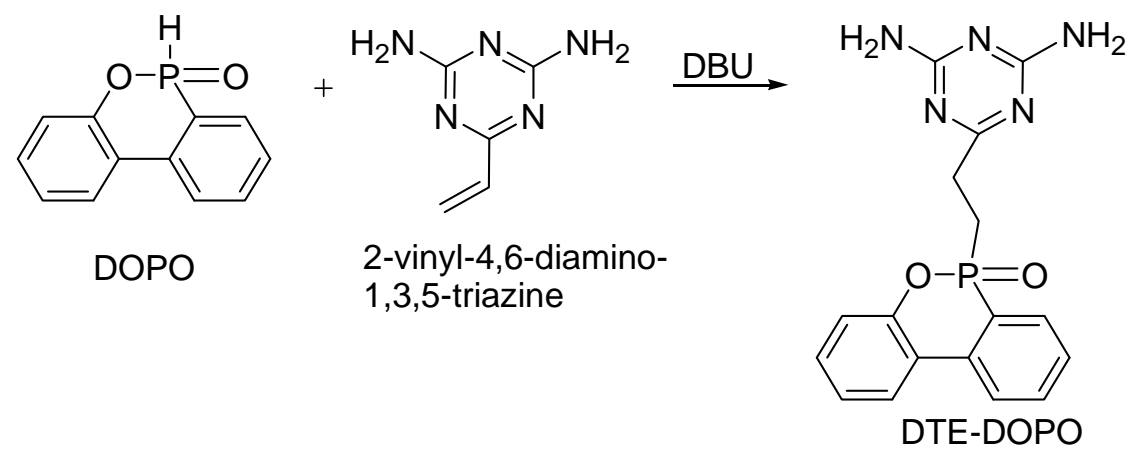

Scheme 1. Synthesis of DTE-DOPO.

\subsection{Melt Processing of PA6 and FR Formulations}

PA6 and FR additives were dried overnight in a vacuum oven at $80^{\circ} \mathrm{C}$ prior to processing. Preliminary screening tests were performed to establish the compatibility and stability of FR additives with PA6 matrix using rheological measurements. Therefore, frequency, amplitude, and temperature sweeps were performed prior to large scale synthesis of DTE-DOPO additive to verify if the FRs can undergo the conditions during extrusion experiments. The compounding of additives with PA 6 was carried out using a $25 \mathrm{~mm}$ co-rotating twin-screw extruder, HAAKE Rheomex OS, having 10 zones and a L/D ratio of 40 . Eight hundreds grams of three different formulations were obtained: neat PA6 (100 wt \% PA6), PA6/DTE-DOPO (82.9 wt \% PA6:17.1 wt \% DTE-DOPO) and PA6/Exolit (83.2 wt \% PA6:16.8 wt \% Exolit ${ }^{\circledR}$ OP 1230). The weight percentages of the FRs were calculated based on the P-content measurements that are described in Section 2.4. The compounding was performed under the following conditions: screw speed of $85 \mathrm{rpm}$, output of $0.8 \mathrm{~kg} / \mathrm{h}$, in a temperature range of $240-250{ }^{\circ} \mathrm{C}$. The extruded threads were cooled in air, pelletized, and dried at $80{ }^{\circ} \mathrm{C}$ for $15 \mathrm{~h}$ under vacuum. A part of the prepared pellets was used to perform thermogravimetric analysis (TGA), differential scanning calorimetry (DSC), pyrolysis combustion flow calorimetry (PCFC), and rheological investigations.

Using a HAAKE MiniJet II injector (Rheology Solutions Pty Ltd., Victoria, Australia) molding, two types of molded (Injection molding machine Battenfeld Plus 350/75, Wittmann Battenfeld, Kottingbrunn, Austria) specimens were obtained: "dog bones" (74 $\mathrm{mm} \times 5 \mathrm{~mm} \times 2 \mathrm{~mm}$ ), used in tensile strength measurements (Instron 5967 machine, Instron, Norwood, MA, USA), and "plates" $(60 \mathrm{~mm} \times 10 \mathrm{~mm} \times 1 \mathrm{~mm})$, used for hardness and impact strength measurement (Rockwell ZWICK/ROELL durometer, Zwick/Roell, Ulm, Germany). Using an injection molding machine Battenfeld Plus 350/75 (Battenfeld Technologies, Columbia, MO, USA), with the temperature profile of the zones between 200 and $250{ }^{\circ} \mathrm{C}$, molded PA6 formulation plates $(125 \mathrm{~mm} \times 13 \mathrm{~mm} \times 1 \mathrm{~mm})$ were 
obtained and used for UL94 vertical flammability tests. No attempts were made to fully optimize the compounding process and the injection molding process.

\subsection{Analytical Characterization}

The structure of DTE-DOPO was characterized by ${ }^{1} \mathrm{H},{ }^{31} \mathrm{P}$, and ${ }^{13} \mathrm{C} \mathrm{NMR}$ recorded on a Bruker Avance 400 NMR spectrometer (Bruker, Coventry, UK), frequencies of 400.13, 100.61, and $161.96 \mathrm{MHz}$, respectively) in DMSO-d $\mathrm{d}_{6}$ at $298 \mathrm{~K}$. Chemical shifts are reported in $\delta$ units (ppm) relative to the remaining resonances of the solvent at $2.49 \mathrm{ppm}\left({ }^{1} \mathrm{H}\right)$ and $39.5 \mathrm{ppm}\left({ }^{13} \mathrm{C}\right)$. The ${ }^{31} \mathrm{P}$ NMR spectra are externally referred to a sample of neat $\mathrm{H}_{3} \mathrm{PO}_{4}$ at $0.0 \mathrm{ppm}$.

High-resolution mass spectrometry (HRMS) analyses were performed using an electronspray ionization (ESI) MS, Bruker's Daltonics SolariX (ESI/MALDI-FTICR-MS, Bremen, Germany) using as matrix 3HPA.

The phosphorus content of the formulations was estimated using the inductively-coupled plasma optical emission spectrometry method (ICP-OES), on a Perkin Elmer Optima 3000 apparatus (Perkin Elmer Inc., Wellesley, UK). Sample preparation for ICP-OES consists of mixing $300 \mathrm{mg}$ of PA6 formulation with $1 \mathrm{~mL} \mathrm{H}_{2} \mathrm{O}_{2}$ and $3 \mathrm{~mL} \mathrm{HNO}_{3}$, followed by etching in the microwave [31].

The rheological properties of the prepared FR/PA6 formulations were investigated using an Anton Paar Physica MCR 301 Rheometer (Anton Paar Physica, Buchs, Switzerland) with plate-plate configuration. The diameter of the measuring plate was $25 \mathrm{~mm}$; the gap was set to $1 \mathrm{~mm}$. The frequency sweeps were carried out within the viscoelastic region of PA6 at $1 \%$ strain and $250{ }^{\circ} \mathrm{C}$, over a frequency range of 500-0.1 rad/s. All measurements were conducted in air environment [32].

The thermogravimetric analysis (TGA) of the additive and the PA6 formulations was carried out using a NETZSCH TG209 F1 Iris instrument (Netzsch, Bonstetten, Switzerland). The sample, weighing approximate $3 \mathrm{mg}$, was heated from 25 to $800{ }^{\circ} \mathrm{C}$ at a heating rate of $10{ }^{\circ} \mathrm{C} / \mathrm{min}$. The measurements were performed under air or nitrogen atmosphere with a total gas flow of $50 \mathrm{~mL} / \mathrm{min}$.

The differential scanning calorimetry (DSC) analyses were performed on a METTLER Toledo DSC822e instrument (Mettler-Toledo, Greifensee, Switzerland) using $40 \mu \mathrm{L}$ Al crucibles. All experiments were conducted in a nitrogen environment keeping a dynamic gas flow of $30 \mathrm{~mL} / \mathrm{min}$. The measurements were performed in three steps: a first heating cycle from 0 to $280{ }^{\circ} \mathrm{C}$; the second step was a cooling cycle from 280 to $0{ }^{\circ} \mathrm{C}$; and the third step was a second heating cycle from 0 to $280{ }^{\circ} \mathrm{C}$. All steps were carried out using a heating rate of $10{ }^{\circ} \mathrm{C} / \mathrm{min}$.

The scanning electron micrographs of PA6 and PA6/FRs formulations were recorded on a Hitachi S-4800 (Hitachi High-Technologies, USA \& Canada) using $2 \mathrm{kV}$ accelerating voltage and $10 \mathrm{~mA}$ current flows. Prior to the measurements, frozen samples were fractured and sputter-coated with $5 \mathrm{~nm}$ gold. For optical microscopy inspection, a Keyence VHX-1000 digital microscope (Keyence Microscope Europe, Mechelen, Belgium) was used in transmission mode.

\subsection{Mechanical Characterization}

The tensile strength was evaluated for the "dog bone" samples according to PN-81/C-89034 standard. Measurement of tensile strength characteristics was made using an Instron 5967 machine (Instron, MA, USA) equipped with a contact extensometer using the head to $1 \mathrm{kN}$. The determination was performed 
at $23{ }^{\circ} \mathrm{C}$, using two tensile speeds of $2 \mathrm{~mm} / \mathrm{min}$ (speed 1) for Young's modulus determination and $50 \mathrm{~mm} / \mathrm{min}$ (speed 2) for tensile strength determination.

The hardness measurement was performed for the plates with a load of $358 \mathrm{~N}$ by using a Rockwell ZWICK/ROELL durometer (Zwick Testing Machines Ltd., Herefordshire, UK) in accordance with EN10109-1 standard. The impact strength measurement was investigated for the plates according to PN-EN ISO 179-1 standard. Determination of notched impact resistance according to Charpy was performed using an impact energy hammer of $1 \mathrm{~J}$ [33].

\subsection{Flame Retardant Characterization}

The combustibility of the materials was determined by pyrolysis combustion flow calorimetry (PCFC) using a FTT instrument (GBH International, Mill Valley, CA, USA). The PA6 samples weighing 1-3 mg were pyrolyzed by heating up to $750{ }^{\circ} \mathrm{C}$, at a heating rate of $1{ }^{\circ} \mathrm{C} / \mathrm{s}$. The combustor of the PCFC instrument was maintained at $900{ }^{\circ} \mathrm{C}$. The specific principle of the PCFC analysis is well described elsewhere [34].

The burning and extinguishing characteristics of all investigated formulations were evaluated by small scale flammability tests. The UL94 vertical burning test was conducted on the injection molded plates $(125 \times 13 \times 1 \mathrm{~mm})$ following the procedure described in ASTM D 3801 norm [35].

Direct insertion probe mass spectrometry (DIP-MS) was used to evaluate possible gas-phase activity and the degradation processes of the FRs. The samples were introduced into a quartz microcup in contact with a heating probe, whose tip was inserted into the ionization chamber, maintained at strongly reduced pressure of $10^{-6}$ mbar. DIP-MS analyses were conducted for 1-2 $\mu \mathrm{g}$ sample using a ThermoQuest FINNIGAN apparatus (Thermo Finnigan/Thermo Scientific, San Diego, CA, USA). The probe was heated from 50 to $450{ }^{\circ} \mathrm{C}$ at a rate of $50{ }^{\circ} \mathrm{C} / \mathrm{min}$. The final temperature was maintained for $4 \mathrm{~min}$.

The measurements of P-content, rheology, and TGA were repeated two times, the PCFC investigations were repeated three times, while the measurements for mechanical properties were the average of five specimens for each formulation. The average values were reported and the error was evaluated as a standard deviation between measurements.

\section{Results and Discussion}

In this study, a meltable, halogen-free, flame-retardant (FR) additive consisting of triazine and DOPO units (DTE-DOPO) was successfully synthesized by the addition reaction of DOPO to 2-vinyl-4,6-diamino-1,3,5-triazine using DBU as catalyst. The compound was evaluated for its chemical structure and thermal properties. Additionally, the effectiveness and the influence of DTE-DOPO on the physical properties of the PA6 formulation were thoroughly investigated and compared with the commercially available FR Exolit ${ }^{\circledR}$ OP 1230.

\subsection{Physical and Chemical Characterization of DTE-DOPO FR Additive}

The melting point of DTE-DOPO, determined by DSC, was identified as a sharp, narrow peak at $257{ }^{\circ} \mathrm{C}$ which is characteristic of a pure compound (Figure S1a in Supplementary files). The melting nature of the additive may have advantage in its subsequent processing with PA6 (processing temp: 
235-250 ${ }^{\circ} \mathrm{C}$ ). The structure of the new FR additive was confirmed by FTIR, HRMS, ${ }^{1} \mathrm{H},{ }^{13} \mathrm{C}$, and ${ }^{31} \mathrm{P}$ NMR spectroscopy measurements. In the FTIR spectrum of DTE-DOPO, absorption bands of both starting reactants appeared, as well as the newly formed $\mathrm{P}-\mathrm{C}$ bond proving the successful addition at carbonyl unit and therefore, the synthesis of the desired structure. Absorption bands characteristic for: $\mathrm{N}-\mathrm{H}$ stretching vibration (3298 and $\left.3101 \mathrm{~cm}^{-1}\right),=\mathrm{C}-\mathrm{H}$ stretching vibration $\left(3060 \mathrm{~cm}^{-1}\right), \mathrm{C}=\mathrm{C}$ aromatic stretching vibration $\left(1649 \mathrm{~cm}^{-1}\right)$, symmetric triazine ring stretching vibration $\left(1538 \mathrm{~cm}^{-1}\right)$, $\mathrm{P}-\mathrm{CH}_{2}$ stretching vibration $\left(1437 \mathrm{~cm}^{-1}\right), \mathrm{P}=\mathrm{O}$ stretching vibration $\left(1184 \mathrm{~cm}^{-1}\right)$, and $\mathrm{P}-\mathrm{O}-\mathrm{Ph}$ stretching vibration $\left(910 \mathrm{~cm}^{-1}\right)$ were identified (Figure S1b in Supplementary files).

In the ${ }^{1} \mathrm{H}$ NMR spectrum characteristic peaks for the amine protons appeared at $6.58 \mathrm{ppm}$, aromatic protons were identified in the range of 7.23-8.21 ppm, while the aliphatic protons were overlapped by the signal of residual water from the solvent (Figure S1c in Supplementary files). In the ${ }^{31} \mathrm{P}$ NMR spectrum a single sharp peak at $37.68 \mathrm{ppm}$ was identified, which proves the existence of a single phosphorus species (Figure S1d in Supplementary files). The ${ }^{13} \mathrm{C}$ NMR data identified the aromatic carbons in the down field region (119.9-175.5 ppm) of the spectrum, while the two aliphatic carbon atoms appeared in the upfield region (24.5-30 ppm) of the spectrum (Figure S1e in Supplementary files). The TGA measurements showed a high thermal stability of DTE-DOPO with the initial decomposition temperature, i.e., the temperature for $5 \%$ weight loss of $355^{\circ} \mathrm{C}$ and a char residue at $700{ }^{\circ} \mathrm{C}$ of $24 \%$, in nitrogen environment (Figure S1f in Supplementary files).

\subsection{Characterization of PA6 Formulations}

A successful strategy to maintain the desired thermal and mechanical properties of the PA6 is to develop a formulation with a minimum loading of the FR additive. The melting behavior of the newly developed DTE-DOPO FR additive is a possible advantage for the compounding process. A meltable additive may exhibit increased compatibility with PA6 in comparison with the non-meltable FR additive Exolit ${ }^{\circledR}$ OP 1230. To evaluate the influence of the new additive on the characteristics of PA6 and to compare its efficiency with the commercial Exolit ${ }^{\circledR}$ OP 1230, a formulation containing Exolit ${ }^{\circledR}$ OP 1230 was also prepared. The two formulations were obtained using compounding by melt extrusion with a loading of $17.1 \%$ additive for the PA6/DTE-DOPO formulation and a corresponding P content of $1.46 \%$, while for the PA6/Exolit formulation the additive loading was of $16.8 \%$ with a $\mathrm{P}$ content of $3.99 \%$. The efficiency of a P-based FR additive is, in general, dependent on the phosphorus content of the formulation. Thus, it should be noted that, for the same additive loading the $\mathrm{P}$ content in the PA6/Exolit formulation is almost three times higher than that of the PA6/DTE-DOPO formulation.

\subsubsection{Rheological Properties}

To evaluate the influence of the additives on the processability and eventual mechanical properties of the formulations, rheological measurements were carried out on the PA6 formulations and on the neat PA6. The loss modulus ( $G$ ") reflects the viscous behavior (liquid-like properties) of the polymer and represents the ability of a material to dissipate energy, while the storage modulus $\left(G^{\prime}\right)$ is a measure for its elasticity (solid-like properties) showing the ability of the polymer to store energy [36].

To compare the flow behavior of thermoplastic formulations it is useful to limit the rheological experiments to the linear viscoelastic region (LVR). According to the strain sweep measurements carried 
out with neat PA6 and both formulations, the complex viscosity $\left(\mu^{*}\right)$ registered a linear plateau in the 1\%-10\% strain region (data not shown). This result determined the selection of $1 \%$ strain for the following rheological measurements.

Analyzing the evolution of $G^{\prime}$ and $G$ ' as a function of the applied frequency (Figure 1a), the loss modulus is almost linear over the whole range of frequencies, while the storage modulus shows a viscoelastic relaxation at low frequencies for both formulations. This deviation from the expected behavior is representative of interfacial interactions between the dispersed FR domains and the polymeric matrix phase, therefore indicating at least a partial miscible blend. As expected, neat PA6 and both PA6 formulations exhibited higher values of loss modulus compared to those of storage modulus in all studied frequency domain, which is typical of a viscous material. The incorporation of Exolit ${ }^{\circledR}$ OP 1230 into PA6 increases the complex viscosity of this formulation and led to higher values of $G$ ' and $G$ ' respect to the neat PA6 (Figure 1b). This could be explained by the limited motion of the polymer chains due to the incorporation of the FR. Contrary to this result, the incorporation of DTE-DOPO additive to PA6 decreases both storage and loss modulus and reduces the complex viscosity when compared to neat PA6 for the whole range of measured frequencies. This might indicate the internal lubricating or plasticizing effect of the additive on the polymer structure, which leads to the improvement in the flexibility of the PA6/DTE-DOPO formulation.
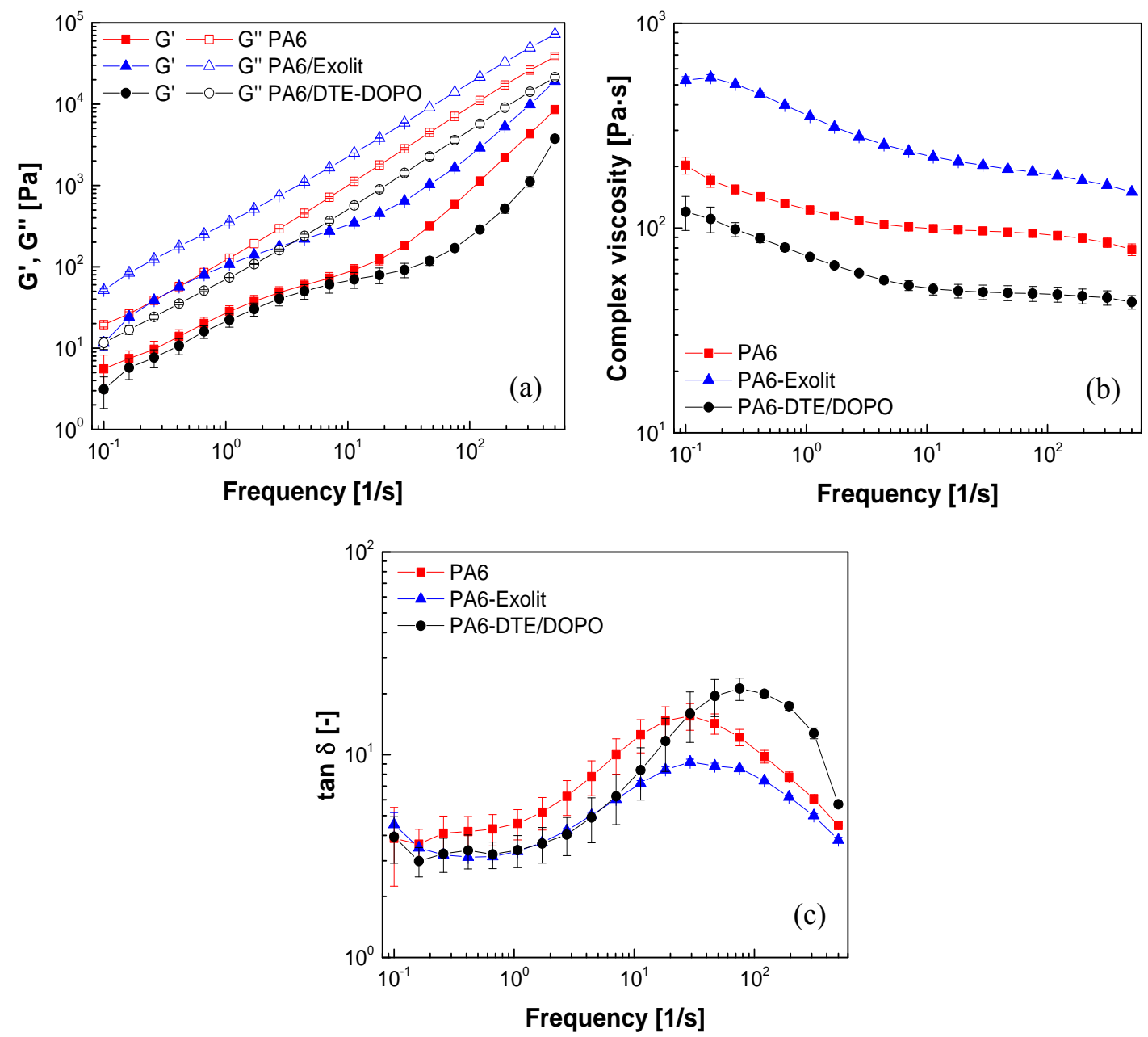

Figure 1. Evolution of (a) loss and storage modulus; (b) complex viscosity; and (c) loss factor $(\tan \delta)$ as a function of frequency for PA6 formulations at $T=250{ }^{\circ} \mathrm{C}$ and $1 \%$ strain. 
From the variation of the loss factor $(\tan \delta)$ with frequency (Figure 1c) it can be noticed that the values of $\tan \delta$ decrease with the introduction of Exolit ${ }^{\circledR}$ OP 1230 into the PA6 formulation, which emphasize the increase in the storage modulus and, therefore, may indicate improved elastic properties by the introduction of this additive. The maximum value of $\tan \delta$ for the PA6/DTE-DOPO formulations shifted to higher frequency compared to that of neat PA6, probably due to changes in the microstructure associated to the addition of the flame retardant.

\subsubsection{Thermal Stability}

The thermal stability of an additive is an important criterion for its application in high-temperature processing of polymers as well as in the final use of the obtained FR material. In the initial stage of combustion, the thermo-oxidative decomposition of flame-retardant polymer is a decisive process due to the presence of a high concentration of oxygen radicals [22]. Moreover, the thermal behavior of a formulation in a free-burning phase of a fire, i.e., when the access to oxygen of the burning material is hindered, is best evaluated in a nitrogen environment. Considering these two different atmospheres, thermogravimetric analysis can simulate the burning conditions as in a UL94 vertical burning test, using a defined heating program and normal pressure. In this context, the thermal decomposition of FR formulations was measured in air (20\% oxygen) and nitrogen environments. The representative TGA curves in $\mathrm{N}_{2}$ of neat PA6 and PA6 formulations, showing the weight loss profile and the corresponding first order derivatives (DTG), are presented in Figure 2. For air conditions, readers are referred to the supplementary files.

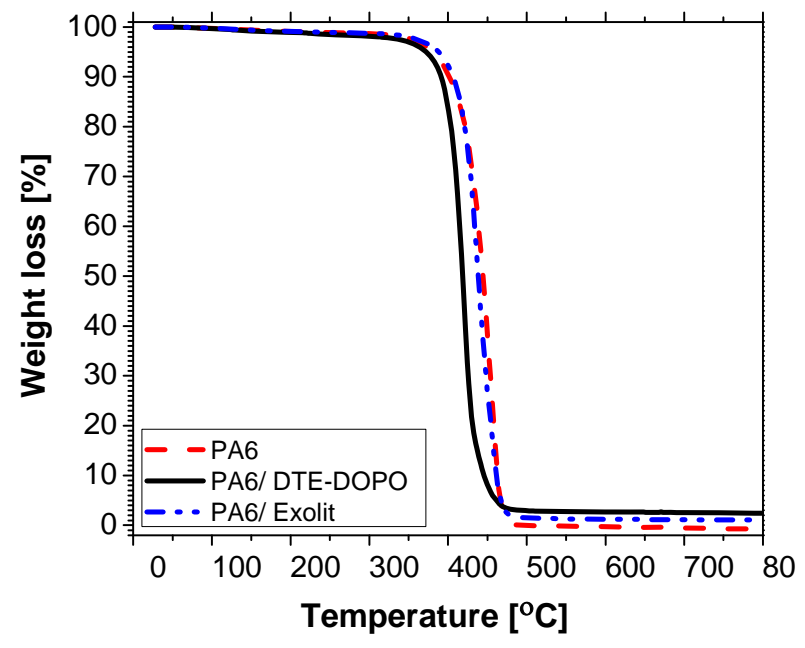

(a)

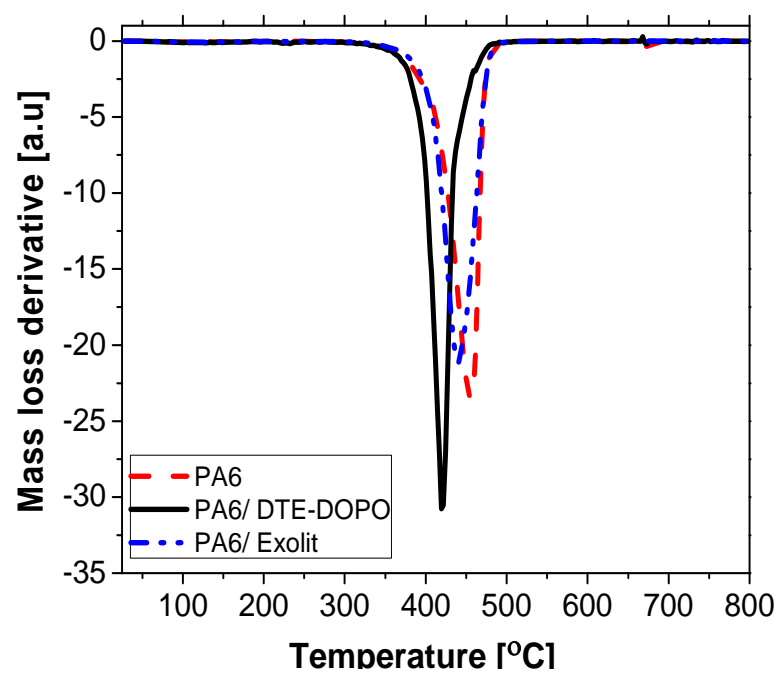

(b)

Figure 2. TGA (a) and DTG curves (b) of PA6 formulations in nitrogen.

The initial decomposition temperature $\left(T_{5}\right)$, the temperature of the maximum mass loss rate $\left(T_{\max }\right)$, estimated on the basis of the DTG maximum peak, and the char yield at $700{ }^{\circ} \mathrm{C}\left(W_{\mathrm{I}}\right)$ measured in both environments are listed in Table 1. 
Table 1. Thermal properties of PA6 formulations in nitrogen and air environment.

\begin{tabular}{|c|c|c|c|c|c|c|}
\hline \multirow{2}{*}{ Sample } & \multicolumn{3}{|c|}{$\mathbf{N}_{2}$ Environment } & \multicolumn{3}{|c|}{ Air Environment } \\
\hline & $T_{5}{ }^{a}\left[{ }^{\circ} \mathbf{C}\right]$ & $T_{\max }{ }^{b}\left[{ }^{\circ} \mathbf{C}\right]$ & $\begin{array}{c}W_{700}{ }^{c}[\mathrm{wt} \\
\%]\end{array}$ & $T_{5}{ }^{\mathrm{a}}\left[{ }^{\circ} \mathbf{C}\right]$ & $T_{\max }{ }^{b}\left[{ }^{\circ} \mathbf{C}\right]$ & $\begin{array}{c}W_{700}{ }^{\mathrm{c}}[\mathrm{wt} \\
\% \text { \%] }\end{array}$ \\
\hline PA6 & $388 \pm 8.4$ & $455 \pm 1.0$ & $0.28 \pm 0.1$ & $382 \pm 2.0$ & $449 \pm 1.0 / 549 \pm 1.0$ & 0 \\
\hline PA6/DTE-DOPO & $372 \pm 0.4$ & $413 \pm 0.8$ & $2.4 \pm 0.3$ & $356 \pm 1.4$ & $\begin{array}{c}406 \pm 0.8 / 547 \pm \\
1.0 / 725 \pm 1.0\end{array}$ & $6.05 \pm 0.01$ \\
\hline PA6/Exolit & $386 \pm 0.8$ & $430 \pm 2.0$ & $0.9 \pm 0.2$ & $373 \pm 1.0$ & $424 \pm 2.0 / 586 \pm 1.4$ & $8.9 \pm 0.1$ \\
\hline
\end{tabular}

${ }^{\mathrm{a}}$ Initial decomposition temperature taken as the $5 \%$ weight loss; ${ }^{\mathrm{b}}$ Temperature of the maximum mass loss rate;

${ }^{\mathrm{c}}$ Char yield at $700{ }^{\circ} \mathrm{C}$.

The thermal decomposition behavior of neat PA6 and PA6 formulations with different FR systems based on non-meltable melamine derivatives has been well studied [7,37-40]. In the nitrogen environment (Figure 2), PA6 has a $T_{5}$ value of approximately $388^{\circ} \mathrm{C}$, decomposed in one stage process with $T_{\max }$ of about $455^{\circ} \mathrm{C}$, leaving negligible char at $700{ }^{\circ} \mathrm{C}(0.28 \mathrm{wt} \%)$, which can be attributed to the partial decomposition of the cross-linked structure at the final stage of the decomposition process. The incorporation of DTE-DOPO in the PA6 has led to a reduction of the initial decomposition temperature $\left(T_{5}=372{ }^{\circ} \mathrm{C}\right)$, while the degradation process registered one step with a decrease of $40{ }^{\circ} \mathrm{C}$ for the temperature of the maximum mass loss rate $\left(T_{\max }=413{ }^{\circ} \mathrm{C}\right)$. The TGA curve registered a steeper slope of the decomposition rate compared to PA6 suggesting a catalyzing effect of DTE-DOPO FR additive on the decomposition of PA6. The highest amount of char was observed for this formulation (2.4 wt \%) as compared to the neat PA6 and to the PA6/ Exolit ${ }^{\circledR}$ OP 1230 formulation. When Exolit ${ }^{\circledR}$ OP 1230 was introduced into PA6 the thermal degradation did not register a significant change as compared to the neat PA6 polymer. Thus, the value of $T_{5}$ was of about $386{ }^{\circ} \mathrm{C}$, the decomposition process registered a single stage with a reduction of $20^{\circ} \mathrm{C}$ in the value of $T_{\max }\left(430^{\circ} \mathrm{C}\right)$, while the char yield had a value of $0.9 \mathrm{wt} \%$. Similar data, regarding the influence of the additive on thermal stability, were obtained for different polymers and FR based on DOPO derivatives [26-28]. The incorporation of various DOPO-based FR additives led to a decrease in thermal stability of the corresponding polymers. This behavior was attributed to the decomposition or vaporization of the FR additive in the initial stage of polymer degradation, and also to the interactions of products obtained from the decomposition reactions of the polymer and additive. In fact, the thermal decomposition of Exolit ${ }^{\circledR}$ OP 1230 in the PA6 formulation might be the result of the degradation of the additive and its vaporization, which might constitute the dominant process [41]. Former studies on PA6 formulations containing melamine or melamine derivatives also reveal an increased destabilization of the PA6 polymer caused by the incorporation of FR additives $[8,38,39]$. Considering the small reduction of $T_{5}$ in the PA6/DTE-DOPO formulation as compared to neat PA6, it seems that the thermal decomposition process of this formulation may be initiated with the release of the FR additive. Additionally, an increased rate of the main degradation process, i.e., sharp curves in the DTG, indicates that the decomposition of the additive may catalyze the scission of the PA6 chains due to the acidic character of the DOPO derivatives [23]. The TGA data in nitrogen suggests that when DTE-DOPO additive was combined with PA6, it resulted in a slight increase in the char formation as compared to the PA6/Exolit ${ }^{\circledR}$ OP 1230 formulation. Additionally, the 
PA6/DTE-DOPO formulation maintains a higher thermal stability. Without a detailed analysis of the decomposition products the evaluation of the FR mechanism of the DTE-DOPO additive in the PA6 formulation is not feasible.

The thermal oxidative degradation behavior of PA6 and PA6 formulations was investigated using a simulated air environment (Figure S2 in Supplementary files). In an air environment the degradation pathway follows a multistep mechanism and more $T_{\max }$ values are registered when compared to a nitrogen environment. These steps correspond to the maximum of different process and not to the global maximum degradation of the whole process.

As expected, the values of $T_{5}$ for all samples slightly decreased compared to the values obtained in $\mathrm{N}_{2}$ atmosphere (Table 1). The degradation process for PA6 and PA6/Exolit formulations exhibited two steps while the PA6/DTE-DOPO formulation presented three steps of decomposition. The earlier decomposition temperature (approximately $7{ }^{\circ} \mathrm{C}$ less than in $\mathrm{N}_{2}$ ) and the increased number of decomposition stages for all PA6 formulations, indicate a thermo-oxidative behavior of all samples. The major decomposition step of PA6 could be observed between 449 and $549{ }^{\circ} \mathrm{C}$ and it is attributed to the volatilization of the small chain fragments and monomer units present in the polymer, which may be related to oxidative-induced cross-linking of the chains. In the case of the PA6/DTE-DOPO formulation, the first degradation step at $406{ }^{\circ} \mathrm{C}$ may be due to the decomposition of the FR additive, the second decomposition step registered at $547^{\circ} \mathrm{C}$ could be attributed to the degradation of the triazine ring, while the third maximum mass loss rate at $725{ }^{\circ} \mathrm{C}$ might be ascribed to the degradation of the remaining products. Literature data also show that the decomposition of the $-\mathrm{NH}_{2}$ unit and of the triazine ring at about 400 and $550{ }^{\circ} \mathrm{C}$, respectively, may lead to the production of nonflammable gas, which can help to the formation of a nonflammable gas barrier region [39]. For the PA6/Exolit formulation, $T_{\max 1}$ observed at $424{ }^{\circ} \mathrm{C}$ may be attributed to the destabilization of polymer chains caused by the decomposition or volatilization of the additive, while $T_{\max 2}$ may be due to the degradation of the system. Such a phenomenon is common for gas-phase active FR for PA6 due to the fire inhibition mechanism of the additives, being attributed by other authors to the formation of volatile diethyl phosphinic acid following the decomposition of its aluminium salt [40,42]. Both PA6 formulations promoted char formation at $700{ }^{\circ} \mathrm{C}$ while the absence of the residue in the case of neat PA6 polymer indicated the total decomposition of polymer into gaseous products. The higher amount of char registered for PA6/Exolit $(8.9 \mathrm{wt} \%)$ when compared to the PA6/DTE-DOPO formulation $(6.05 \mathrm{wt} \%)$ may be due to the generation of polyphosphoric acid and its salts in the case of Exolit ${ }^{\circledR}$ OP 1230, which facilitates the formation of the carbonaceous layer [43]. It is known that the introduction of melamine destabilizes PA6 and leaves no char residue above $600{ }^{\circ} \mathrm{C}$, while DOPO-based FR can exhibit both condensed and gas phase activity $[8,41]$. The $6.05 \mathrm{wt} \%$ char in the case of PA6/DTE-DOPO could be explained by the chemical modification of the melamine derivative which enables, as expected from the TGA data of the additive, the promotion of a carbonaceous layer. Higher values for char residue in air were found by other authors for the analyzed PA6,6/OMMT nanoclay system. They concluded that the barrier effect of the silicate layer had a large contribution in the formation of carbonaceous char on the surface of the nanocomposite [44]. The amount of char obtained in the case of the PA6/DTE-DOPO formulation may indicate, to a certain extent, a condensed-phase activity. Further decomposition studies using PCFC and 
DIP-MS measurements were carried out to understand the mode of action of the FR additive and will be discussed in detailed in the following sections.

Incorporation of FR additives in PA6 by means of compounding may change the physical and structural properties of the polymer due to the use of heat and shear stress during processing. DSC measurements were used to identify the changes in the molecular structure based on the melting behavior of PA6 formulations. It is known that DSC curves obtained from the first heating cycle reflect the influence of processing conditions, storage conditions and/or sample preparation. Some subtle thermal transitions like side group rotations, segmental motions of the polymer chain, and the specific details of the melting endotherm may be caused by the process history. Therefore, it is important to compare a second heating cycle DSC curve with the first one to distinguish properties characteristic of the polymer with those properties imparted by the process [45]. The results obtained from the first heating cycle (Figure 3a) provide information regarding the melting characteristics which influences the mechanical properties of the formulation [46-48].
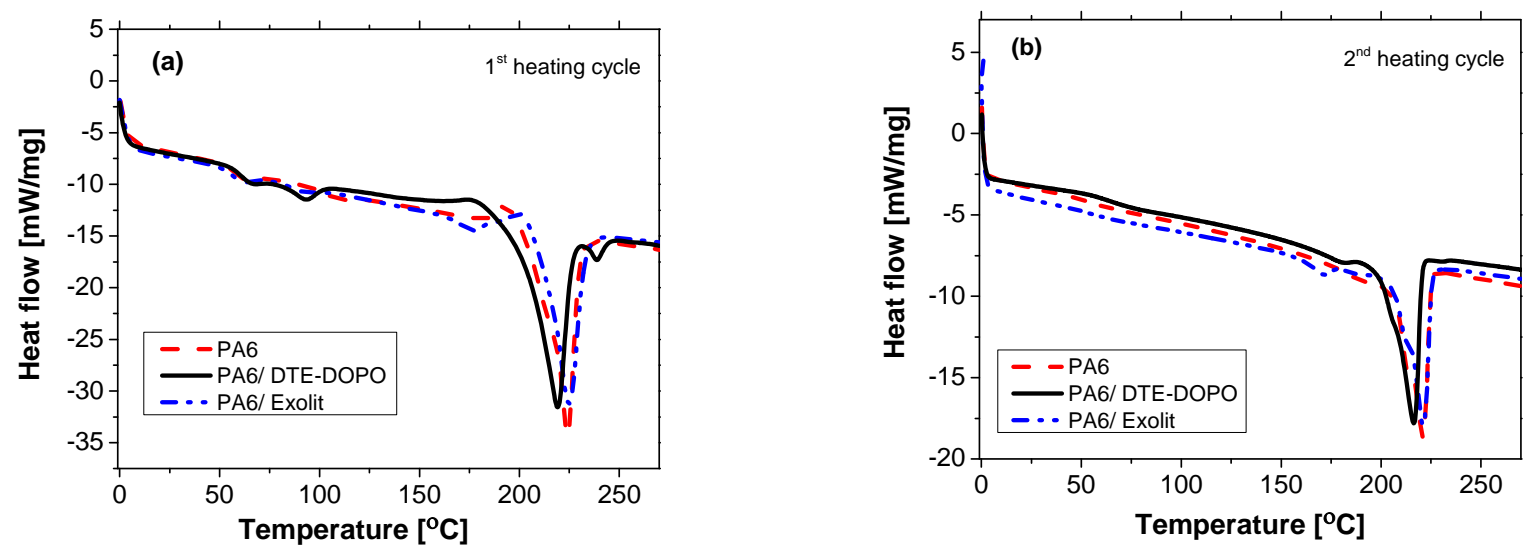

Figure 3. DSC measurements for PA6 formulations on first (a) and second (b) heating scan.

The endothermic peak at $224{ }^{\circ} \mathrm{C}$ registered for neat PA6 was attributed to the melting of $\alpha$-phase crystals. Compared to the base polymer, the peak for the PA6/DTE-DOPO formulation shifted to $219^{\circ} \mathrm{C}$, while the peak for PA6/Exolit sample was found in the same region as in PA6, at $224.9^{\circ} \mathrm{C}$. As mentioned earlier, the nature of the peaks registered at 65,94 , and $239{ }^{\circ} \mathrm{C}$ for PA6/DTE-DOPO during the first heating may be explained by the influence of processing. The two small endothermic peaks registered below $100{ }^{\circ} \mathrm{C}$ may be caused by the evaporation of absorbed water from the PA6 polymer, while the small peak after the melting process may be due to a subtle thermal transition. These peaks do not appear in the second heating curve, i.e., when the thermal history of the polymer has been deleted, confirming the effect of processing. The decrease of melting point for the DTE-DOPO formulation may be attributed to the incorporation of the meltable additive which acts as a plasticizer reducing the density of the amide group interactions, which has direct influence on the ability of forming hydrogen bonding. Thus, as a result of the decreased value of melting point of the PA6/DTE-DOPO formulation, lower processing temperatures could be applied in the compounding step of PA6 and the DTE-DOPO additive. However, due to the non-melting nature of Exolit OP1230, those lower processing temperatures would produce rather inhomogeneous formulations of PA6/Exolit as a result of the limiting interaction of polymer chains with the additive. 
The curves recorded in the second heating cycle (Figure $3 \mathrm{~b}$ ) give information regarding the possible interaction between PA6 and FR additives. The values obtained for the melting temperature of the PA6 formulations were similar to those registered in the first heating cycle: $220.9{ }^{\circ} \mathrm{C}$ for neat PA6, $216.3{ }^{\circ} \mathrm{C}$ for PA6/DTE-DOPO, and $221{ }^{\circ} \mathrm{C}$ for PA6/Exolit. The similarity in shape and position of the melting peaks exhibited in both heating cycles indicate that no polymer degradation happened during thermal processing.

\subsubsection{Mechanical Properties of PA6 Formulations}

The incorporation of FR additives may influence the mechanical properties of the PA6 formulations as indicated by rheological and DSC measurements. Therefore, various mechanical tests were performed to investigate the effect of introduction of FR additives. The results for neat PA6 and PA6 formulations containing FR additives are listed in Table 2.

Table 2. Mechanical properties of PA6 formulations.

\begin{tabular}{cccccc}
\hline Sample & $\begin{array}{c}\text { Yield strength } \\
{[\mathrm{MPa}]}\end{array}$ & $\begin{array}{c}\text { Elongation at } \\
\text { yield strength [\%] }\end{array}$ & $\begin{array}{c}\text { Young's } \\
\text { modulus [GPa] }\end{array}$ & $\begin{array}{c}\text { Hardness } \\
{[\mathbf{M P a}]}\end{array}$ & $\begin{array}{c}\text { Impact strength } \\
{\left[\mathbf{k J} / \mathbf{m}^{2}\right]}\end{array}$ \\
\hline PA6 & $62.5 \pm 6.9$ & $6.5 \pm 1.0$ & $1.19 \pm 0.11$ & $144.4 \pm 4.9$ & do not break \\
PA6/DTE-DOPO & $69.1 \pm 6.6$ & $6.3 \pm 0.7$ & $1.25 \pm 0.06$ & $162.1 \pm 9.1$ & $4.53 \pm 0.11$ \\
PA6/Exolit & $47.3 \pm 6.2$ & $6.2 \pm 1.2$ & $1.17 \pm 0.03$ & $136.7 \pm 5.0$ & $5.58 \pm 0.06$ \\
\hline
\end{tabular}

It can be observed that the introduction of the DTE-DOPO FR additive in the PA6 has a slight reinforcing effect due to the increased value of yield strength (69.07 MPa) while the elongation at yield strength $(6.3 \%)$ is similar in comparison to PA6. In contrast, the incorporation of Exolit ${ }^{\circledR}$ OP 1230 has led to a significant decrease in the yield strength (47.3 MPa), indicating that permanent deformation occurs at lower stress for this formulation.

The evaluation of the Young's modulus showed higher mean values for PA6/DTE-DOPO (1.25 GPa) with respect to neat PA6 (1.19 GPa) and the PA6/Exolit formulation (1.17 GPa), demonstrating that the incorporation of DTE-DOPO into PA6 helps in obtaining a more rigid material. Moreover, the hardness, defined as a material's resistance of its surface to the penetration of a harder body, was as well higher for PA6/DTE-DOPO (162 MPa). On the contrary, the PA6-Exolit formulation exhibited the lowest of the hardness values. This result sustains the higher resistance of the newly-developed DTE-DOPO FR additive which exhibits a strengthening effect on PA6.

Finally, the results from the impact strength measurements showed no breaking for neat PA6, while PA6/DTE-DOPO and PA6/Exolit formulations registered values of $4.53 \mathrm{~kJ} / \mathrm{m}^{2}$ and $5.58 \mathrm{~kJ} / \mathrm{m}^{2}$, respectively. Observing SEM images the cryogenic fracture of the formulations, one can distinguish distinct lines of fracture propagation for the DTE-DOPO formulation which are associated to an inherent brittleness. Contrary, the other formulations do not present such distinct lines, confirming the lower toughness of the DTE-DOPO formulation. This corroborates the decrease of toughness for the formulation containing DTE-DOPO what can also be observed in the SEM image from the fracture at liquid nitrogen temperature of PA6/DTE-DOPO formulation (Figure 4), as well as from the lowest 
complex modulus $\left(G^{*}\right)$ of this formulation obtained from the rheological measurements (Figure S3 in Supplementary files).

The results are similar with the data obtained by rheological measurements where lower values of the loss modulus were registered as compared to neat PA6, suggesting a good interfacial compatibility which restricts the movement of the chain segments, resulting in a lower toughness [49]. The better compatibility of the PA6/DTE-DOPO formulation when compared to PA6/Exolit may be explained by the nature of the two FR additives: DTE-DOPO melts during the compounding process enabling a better homogeneity with PA6, while Exolit ${ }^{\circledR}$ OP 1230 is a non-meltable salt which may lead to a less uniform distribution in the polymer matrix. To corroborate this statement the distribution of FR additives within the PA6 matrix was analyzed. As can be seen in Figure 5 the microstructure of the PA6/DTE-DOPO formulation is similar to the neat PA6 while the non-melted Exolit ${ }^{\circledR}$ OP 1230 particles are clearly visible in PA6/Exolit formulation.

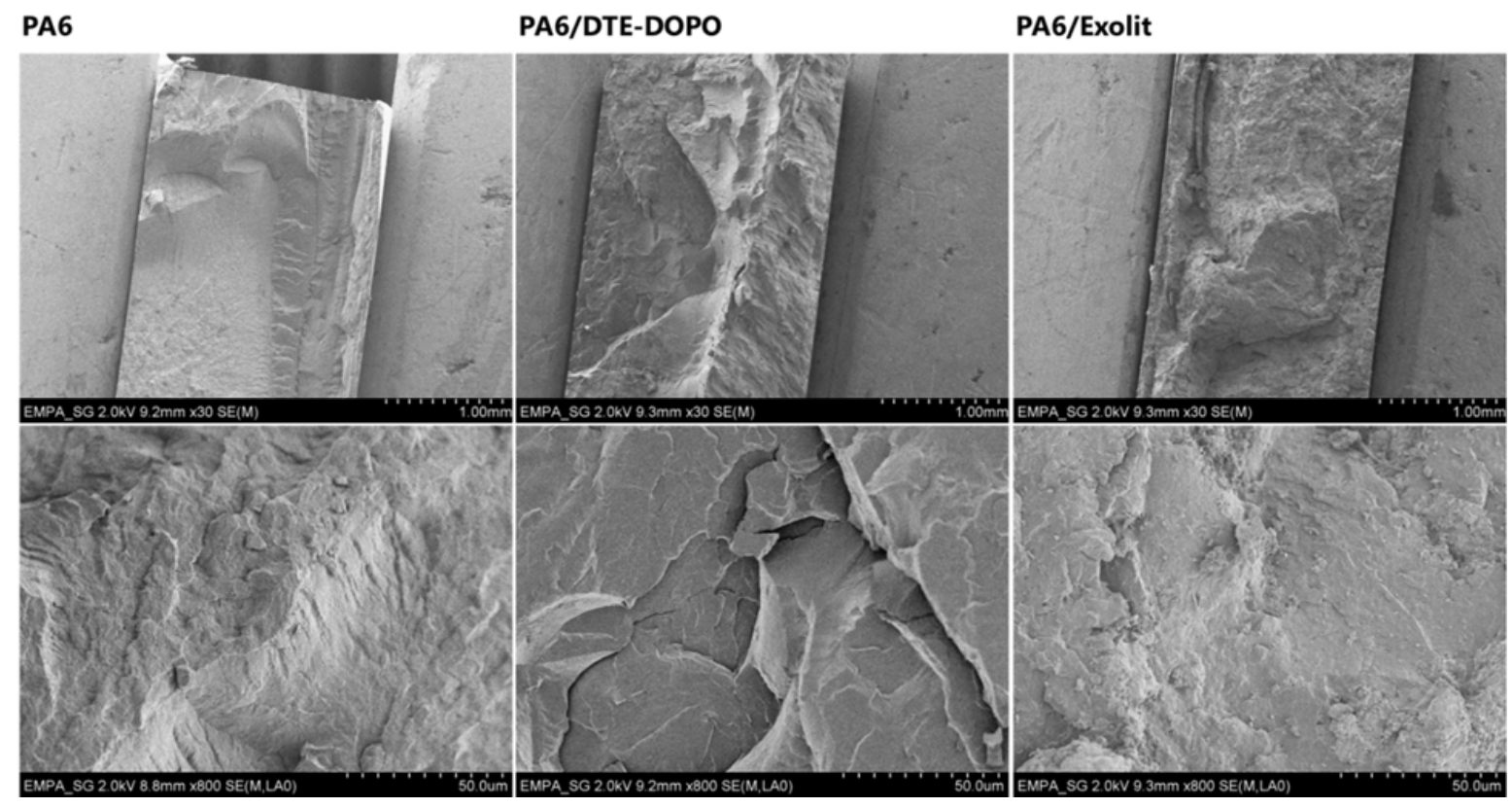

Figure 4. SEM images of the fracture of neat PA6 and PA6/ FRs formulations after their treatment in liquid $\mathrm{N}_{2}$. Upper row shows the images of the materials located in between the walls of the metallic holder. Lower row presents higher magnification images.
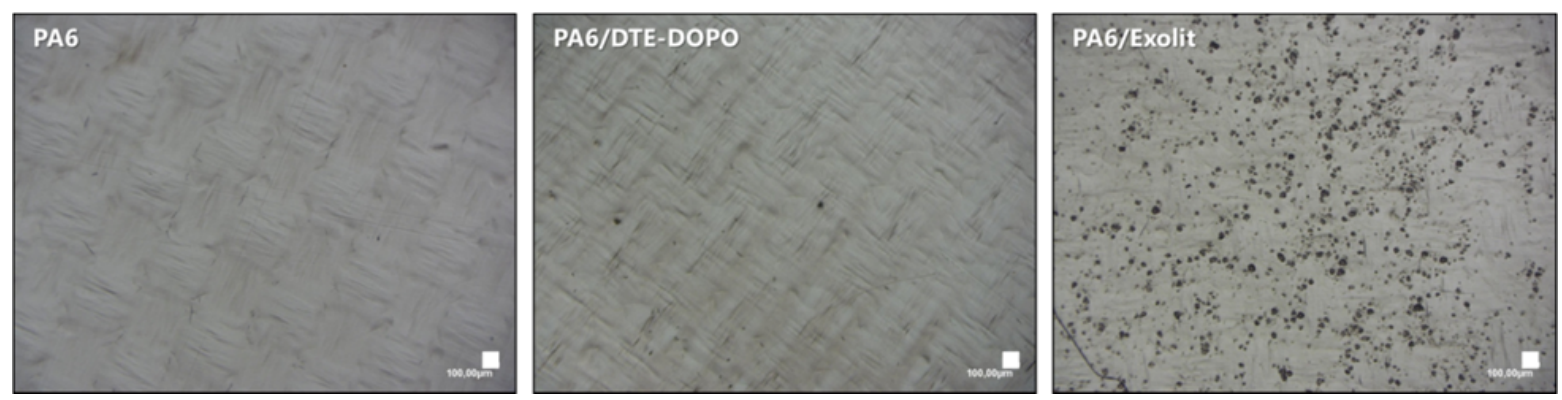

Figure 5. Transmission optical microscope images of the films prepared from PA6, PA6/DTE-DOPO, and PA6/Exolit formulations by hot compression at $240{ }^{\circ} \mathrm{C}$ for $5 \mathrm{~min}$. Bar scales represent $100 \mu \mathrm{m}$. For the PA6/Exolit formulation the black points of the image account for the distribution of the Exolit particles within the PA6 matrix. 


\subsubsection{Flame Retardancy of PA6 Formulations-PCFC and UL94 Tests}

PCFC is a complimentary technique of cone calorimetry which investigates the combustion behavior and the efficiency of flame retardants. The main results obtained from the PCFC measurements (Table 3 and Figure 6) are the peak of the heat release rate $(p H R R)$ defined as the heat release rate divided by the constant heating rate, the temperature at the maximum heat release rate $\left(T_{\mathrm{M}}\right)$ and the total heat released per unit initial mass $(T H R)[50]$.
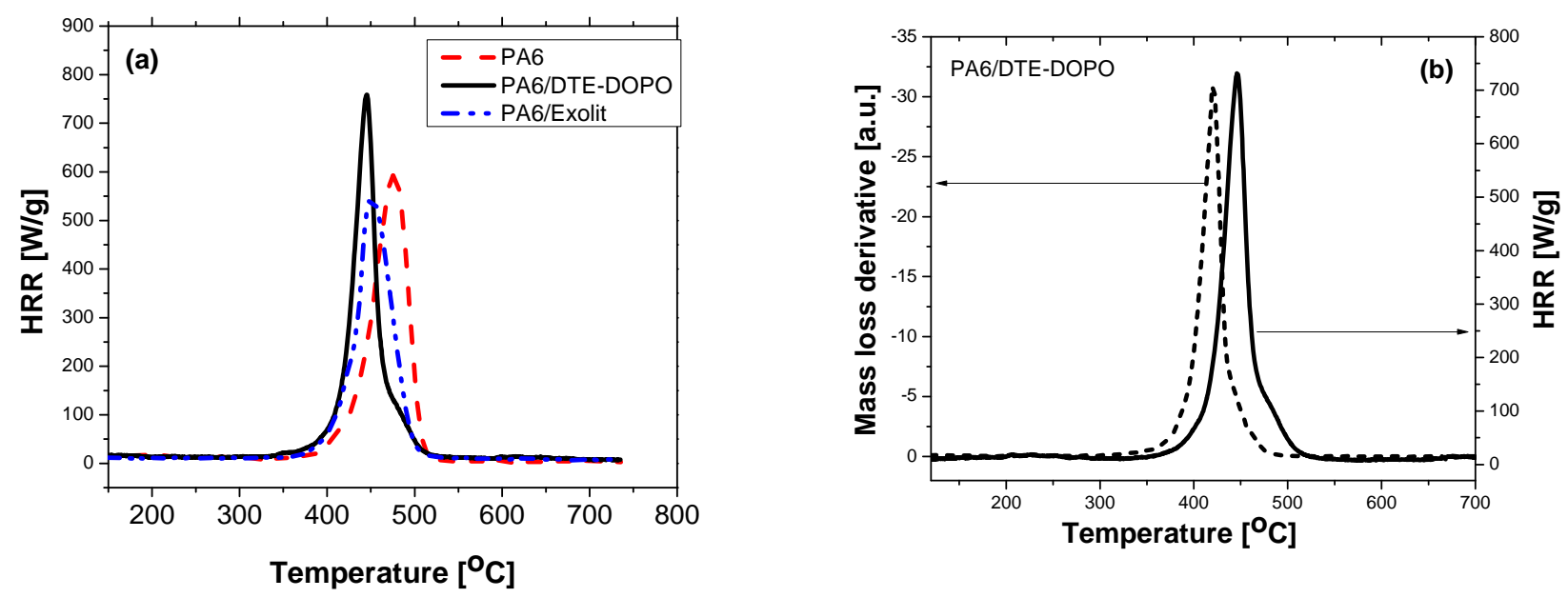

Figure 6. HRR versus temperature for PA6 formulations (a) and comparative HRR and mass loss derivative for the PA6/DTE-DOPO formulation (b).

Table 3. PCFC data for PA6 and PA6 formulations.

\begin{tabular}{cccccc}
\hline Sample & $\begin{array}{c}\boldsymbol{T}_{\mathbf{M}}{ }^{\mathbf{a}} \\
{\left[{ }^{\circ} \mathbf{C}\right]}\end{array}$ & $\begin{array}{c}\boldsymbol{p H R R}^{\mathbf{b}} \\
{[\mathbf{W} / \mathbf{g}]}\end{array}$ & $\begin{array}{c}\boldsymbol{T H R}^{\mathbf{c}} \\
{[\mathbf{k J} / \mathbf{g}]}\end{array}$ & $\begin{array}{c}\mathbf{W}_{\mathbf{8 0 0}}{ }^{\mathbf{d}} \\
{[\%]}\end{array}$ & $\begin{array}{c}\mathbf{P}^{\mathbf{\%}} \text { content } \\
{[\mathbf{w t} \boldsymbol{\%}]}\end{array}$ \\
\hline PA6 & $476.5 \pm 0.2$ & $590 \pm 8.4$ & $28.5 \pm 0.2$ & $1.01 \pm 0.9$ & 0 \\
PA6/DTE-DOPO & $445.5 \pm 0.3$ & $738 \pm 14$ & $27.4 \pm 1.6$ & $3.77 \pm 0.9$ & $1.46 \pm 0.08$ \\
PA6/Exolit & $450.9 \pm 1.7$ & $538 \pm 14$ & $27.4 \pm 0.6$ & $1.41 \pm 0.9$ & $3.99 \pm 0.07$ \\
\hline
\end{tabular}

a The temperature at the maximum heat release rate; ${ }^{b}$ Peak heat release rate; ${ }^{c}$ Total heat release; ${ }^{d}$ Residue at $800{ }^{\circ} \mathrm{C}$.

For neat PA6 the value for the peak heat release rate $(p H R R)$ was of about $590 \mathrm{~W} / \mathrm{g}$ at a temperature of $476{ }^{\circ} \mathrm{C}$, for the PA6/DTE-DOPO formulation the $p H R R$ registered a value of $738 \mathrm{~W} / \mathrm{g}$ at a $T_{\mathrm{M}}$ of about $445{ }^{\circ} \mathrm{C}$, while for the PA6/Exolit formulation the peak heat release rate was $538 \mathrm{~W} / \mathrm{g}$ at a temperature of $451{ }^{\circ} \mathrm{C}$. Thus, it can be noticed that the newly-developed triazine-DOPO-based PA6/FR formulation has a higher value of peak heat release rate as compared to the neat PA6, while the PA6 formulation based on the commercially available flame retardant Exolit ${ }^{\circledR}$ OP 1230 registered a lower value of $p H R R$ as compared to the base polymer (Figure 6a). For both FR additives, the temperature for peak heat release rate decreased compared to the virgin PA6, i.e., 31 and $26{ }^{\circ} \mathrm{C}$ less for PA6/DTE-DOPO and PA6/Exolit, respectively. The increase in the value of $p H R R$ might indicate limited condensed phase effect and a primary gas-phase mechanism of flame inhibition in the case of PA6/DTE-DOPO formulation, while the reduction of $p H R R$ for PA6/Exolit formulation may be 
correlated with a comparatively higher condensed-phase activity. Increased $p H R R$ for PA6/DTE-DOPO formulation observed in PCFC correlates well with the TGA data (DTG curves) presented earlier. This may be due to catalytic decomposition of the PA6 resulting from the interaction of PA6 with the acidic DOPO derivatives. Charring in fire is an anaerobic process, so that the residues obtained after PCFC measurements might be an indication for an additional evidence of a condensed-phase activity in case of the PA6/DTE-DOPO as presented in Table 3. Other studies based on the PA6 formulation containing organic phosphinate also concluded an additional gas-phase activity for the formulation containing Exolit ${ }^{\circledR}$ OP 1230 additive as a result of the release of phosphinic acid derivatives. The authors suggested that Exolit ${ }^{\circledR}$ OP 1230 decomposes, forming diethylphosphinic acid and ethane in vapor phase and aluminium phosphates acts in condensed phase [51]. Thus, a combined gas and condensed-phase activity can be considered for our PA6/Exolit formulation.

Since constant heating rates are used in both the PCFC and TGA methods, the heat release rate in the PCFC is related to the mass loss rate observed in TGA measurements. In Figure $6 \mathrm{~b}$ is presented the heat release rate data together with the mass loss derivative (in $\mathrm{N}_{2}$ ) for the PA6/DTE-DOPO formulation. A very good correlation was observed: the thermal degradation exhibited one-step in both curves, while the temperature at the maximum heat release rate was shifted to higher temperatures because of the higher heating rate used in the PCFC $\left(60^{\circ} \mathrm{C} / \mathrm{min}\right.$ for PCFC versus $10^{\circ} \mathrm{C} / \mathrm{min}$ for TGA). Thus, PCFC delivered similar information as the TGA, but in the form of the heat release rate, which is the accepted measure for fire risks [52].

From the parameters registered by PCFC, a good predictor of combustion efficiency is the total heat release (THR). A slight decrease in THR for the PA6 formulations compared to the neat PA6 is a possible evidence for the improvement of flame spread and fire load [53]. Both PA6 formulations registered a reduction in the mean value of $T H R$ of approximately $1 \mathrm{~kJ} / \mathrm{g}$ relative to PA6 (Table 3). Therefore, based on the THR values obtained from the PCFC measurements it can be assumed that the newly-developed DTE-DOPO FR additive may exhibit a similar flame-retardant behavior compared to Exolit ${ }^{\circledR}$ OP 1230. In addition, phosphorus content is a determining factor in the efficiency of P containing FRs [12,22]. From the data reported in Table 3 it is obvious that the P content of the PA6/DTE-DOPO formulation $(1.46 \%)$ is nearly three times lower compared to the PA6/Exolit formulation (3.99\%), at a similar FR additive weight percent loading. Therefore, their comparable effectiveness of flame retardancy may suggest a good performance of the triazine-DOPO-based FR additive. The flame-retardant efficiency of the new DTE-DOPO-based FR in PA6 might be also facilitated by the release of melamine derivatives through the decomposition of FR additive resulting in a dilution of fuel, as implied by the TGA analysis. It is known that an efficient gas-phase flame-retardant activity is determined by the release in the same temperature range of both FR additive and the decomposition products of the polymer [26]. Therefore, the slight reduction of thermal stability of the triazine-DOPO-based FR compared to neat PA6 may support a gas-phase fire inhibition mechanism.

It should be mentioned that the well-defined conditions of the combustion in PCFC differ essentially from the small scale fire tests in which the fire behavior of the sample also controls the fire scenario. Important fire retardancy mechanisms, such as flame inhibition in the gas phase are active in real fires but not in the complete combustion from the PCFC measurements. While PCFC is a reasonable approach for measurements within the mg-scale with respect to characterizing the intrinsic fire hazard of a material, 
it cannot replace tests like LOI, UL 94 or the cone calorimeter. PCFC does not measure important physical effects occurring on larger scales, such as dripping, wicking, barrier formation, insulation and flame inhibition. Thus, combining the PCFC data with results from other small scale fire tests enables a quantitative insight into the effectiveness of charring and flame inhibition.

The UL 94 test was also used to determine the efficiency of FRs since it is the most important and widely used method for screening the flammability of polymeric materials. It measures the resistance to sustain ignition by a small flame in a specific, well-defined scenario rather than evaluating a material property. UL 94 flame resistance is determined not only by the thermal combustion properties measured in the PCFC but also by factors such as the viscosity of the melt, which determines dripping behavior, thermal conductivity, specific heat, and the specimen geometry [35]. The relevant data obtained by UL 94 test are presented in Table 4.

Table 4. Results of UL94 flammability test for PA6 formulations.

\begin{tabular}{cccc}
\hline Sample & Rating & Cotton ignition & $\mathbf{t}_{\mathbf{1}} \mathbf{a}^{\mathbf{a}} \mathbf{t}_{\mathbf{2}} \mathbf{b}[\mathbf{s}]$ \\
\hline PA6 & V2 & yes & $2 / 0$ \\
PA6/DTE-DOPO & V0 & no & $0 / 0$ \\
PA6/Exolit & V0 & no & $2 / 3$ \\
\hline
\end{tabular}

a Afterflame time registered in the first flame application; ${ }^{b}$ Afterflame time registered in the second flame application.

As expected, PA6 exhibited a self-sustained burning behavior achieving a V2 rating (due to the ignition of the cotton placed under the sample). As a result the recorded afterflame time for the first flame application $\left(t_{1}\right)$ was of $2 \mathrm{~s}$. No significant char formation was observed during the UL 94 test, similar to the results obtained by TGA analyses in air. The best test results in terms of rating and afterflame times were obtained in the case of the PA6/DTE-DOPO formulation. No burning drips were observed which led to an eventual V0 classification. Lower concentration of DTE-DOPO (i.e., 15\%) resulted in V2 ratings and thus the experimental data related to this formulation is not presented in this work. The absence of afterflame times and the formation of non-burning residue are solid evidence for the gas-phase fire inhibition of the DTE-DOPO additive. Therefore, the observations drawn by UL 94 test are consistent with the ones obtained by PCFC and TGA measurements. In the case of the PA6/Exolit formulation a V0 rating was also achieved but the recorded afterflame times $\left(t_{1} / t_{2}=2 / 3 \mathrm{~s}\right)$ indicated that the self-sustained burning was not fully suppressed. It is known that as the degradation of polymer chains occurs, low viscosity melt drips are formed, which may result in the reduction of the exothermic effect caused by the combustion process. Thus, when the melted polymer drips away from the burning material, the heat is removed from the sample leading to the extinction of fire. Along with the observations obtained from the PCFC and TGA measurements, namely a decrease value of total heat release and a comparable thermal stability, it can be inferred that the enhanced flame resistance of the DTE-DOPO FR additive may be mainly due to a gas-phase activity. The slight char residue observed in both TGA and PCFC experiments together with the non-burning melted drips observed in UL 94 test may support an additional condensed phase mechanism of the additive. 


\subsubsection{Direct Insertion Probe Mass Spectrometry (DIP-MS)}

Combining the data obtained from TGA, PCFC, and UL 94 tests a predominant gas-phase action for the DTE-DOPO FR additive seems to be dominant in the improvement of fire performance for PA6/DTE-DOPO formulation. In general, an effective flame retardant additive should decompose and release active species in the gas phase at a temperature close to the degradation temperature of the polymer matrix [26]. Thus, to further analyze the flame retardant behavior of the additives, direct insertion probe mass spectrometry measurements were performed to identify the volatile products released during the thermal decomposition of PA6 formulations.

From Figure $7 \mathrm{a}$ it can be noticed that the PA6/DTE-DOPO formulation decomposes or volatizes earlier compared to PA6 and PA6/Exolit formulations, as expected from the initial decomposition temperature measured by TGA. The PA6/DTE-DOPO formulation starts to volatilize or decompose at about $4.6 \mathrm{~min}$ and has a maximum decomposition rate at $8.9 \mathrm{~min}$ which corresponds to a temperature of approximately $440{ }^{\circ} \mathrm{C}$. After $11 \mathrm{~min}$ most of the FR additive was released in the gas phase, but a certain amount of DTE-DOPO may still remain in the polymer. This was also suggested by the condensed phase activity showed in TGA, PCFC, and UL 94 measurements. The catalyzing effect of the DTE-DOPO additive on the PA6 formulation shown in TGA behavior can be also observed in the DIP-MS curve, while the efficiency can be confirmed by the long-term presence of the additive in the system (about $6 \mathrm{~min}$ ). The PA6/Exolit formulation starts to decompose and volatilize at $c a .9 \mathrm{~min}$, in the same temperature range of PA6, which corresponds to a temperature of approximately $450{ }^{\circ} \mathrm{C}$, while the maximum intensity cannot be detected due to the limitation of the instrument settings.

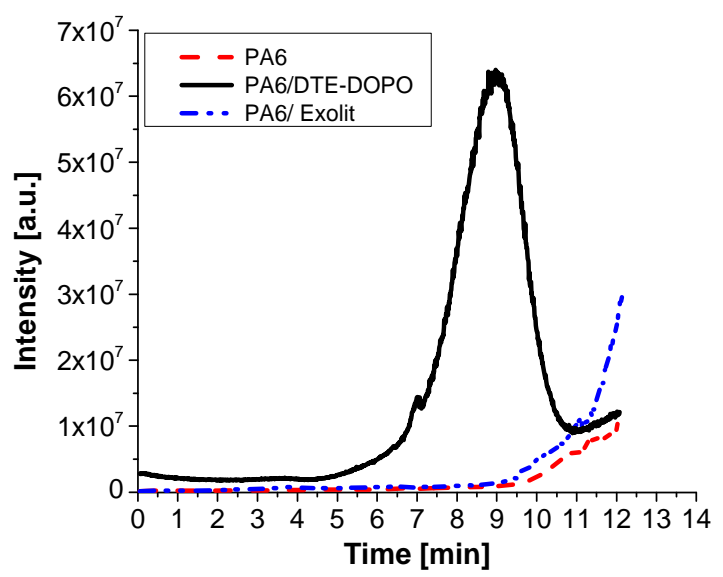

(a)

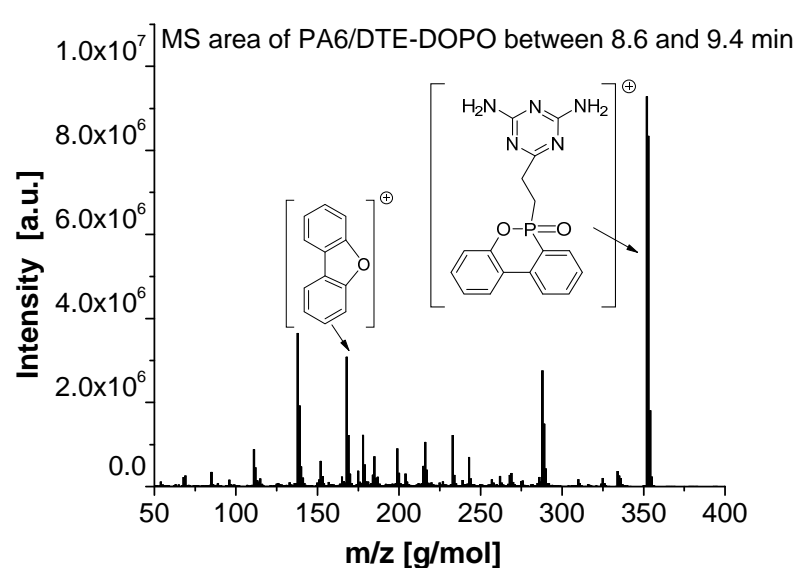

(b)

Figure 7. DIP-MS data of PA6 formulations: total ion chromatogram (a) and the corresponding mass profile between 8.6 and $9.4 \mathrm{~min}$ (b).

Extracted MS data from total ion chromatogram of the PA6/DTE-DOPO formulation between 8.6 and 9.4 min are presented in Figure 7b. It can be observed that the DTE-DOPO FR additive is present as the predominant product in the gas phase as well as some other fragments with a lower intensity, which enhances its flame inhibition action. 


\section{Conclusions}

A new meltable, halogen-free, triazine-DOPO (DTE-DOPO)-based flame retardant for PA6 was synthesized, characterized and its flame retardant efficiency was compared with a non-meltable commercially available additive Exolit ${ }^{\circledR}$ OP 1230 . Two formulations were obtained using compounding by melt extrusion with an additive loading of $17.1 \%$ for the PA6/DTE-DOPO formulation (P content of $1.46 \%$ ), and of $16.8 \%$ for the PA6/Exolit formulation ( $\mathrm{P}$ content of 3.99\%). The rheological measurements evidenced a plasticizing effect for PA6/DTE-DOPO while, for the PA6/Exolit formulation, an interfacial compatibility could be observed, data which were confirmed by the mechanical investigations. Mechanical properties suggested a strengthening effect and a decrease of toughness of PA6/DTE-DOPO formulations, compared to neat PA6 and the PA6/Exolit formulation. By analyzing the distribution of FR additives in PA6 matrix a better compatibility and a higher homogeneity was observed for PA6/DTE-DOPO when compared to the PA6/Exolit formulation. Thermal analysis of the PA6/DTE-DOPO formulation showed a slight decrease of initial decomposition temperature when compared to the other samples. Also the main degradation process indicated that the decomposition of the DTE-DOPO additive at the early stage may catalyze the scission of the PA6 chains, facilitating the predominant gas-phase mechanism and a slight condensed-phase activity (increased char yield). PCFC suggested a combined gas- and condensed-phase activity for both PA6/DTE-DOPO and PA6/Exolit formulations. UL 94 tests produced a V0 rating for both formulations but PA6/DTE-DOPO showed no afterflame times as compared to the commercially available additive. This last result further suggests that the new FR fully suppresses the self-sustained burning of PA6. DIP-MS data correlates well with the TGA, PCFC and UL 94 tests results and provides further evidence of predominant gas-phase activity for both additives. All the data suggested that DTE-DOPO can be used as successful flame retardant for PA6, especially for those applications which require clarity of the final PA6 FR formulation.

\section{Supplementary Materials}

Supplementary materials can be accessed at: http://www.mdpi.com/2073-4360/7/8/1469/s1. Figure S1a-f presents the DSC curve, FT-IR, ${ }^{1} \mathrm{H}$ NMR, ${ }^{13} \mathrm{C}$ NMR, ${ }^{31} \mathrm{P}$ NMR spectra and TGA curves of DTE-DOPO. Figure S2 exhibits the TGA curves of PA6 formulations in air. Figure S3 shows the evolution of complex modulus versus frequency for PA6 formulations.

\section{Acknowledgments}

The financial support provided from SCIEX Project No. 12379 is gratefully acknowledged. The authors thank to Daniel Rentsch from Empa, Dübendorf for NMR analysis, to Matthias Lienhard for his assistance in polymer processing, and to Timea Stelzig, Aleksandra Buczko, Khalifah Salmeia, Elisabeth Michel all from Empa, St. Gallen for their support in conducting various analytical measurements. 


\section{Author Contributions}

Irina Butnaru performed the synthesis of the new additive, interpreted the experimental results and wrote the paper, María P. Fernández-Ronco performed the rheological and morphological characterization of the formulations and contributed to the analysis of the results and to the writing of the manuscript, Justyna Czech-Polak made the molded plates and performed the mechanical tests, while Maciej Heneczkowski and Maria Bruma contributed to discussions. Sabyasachi Gaan contributed to edition of the paper and was the leader of the study.

\section{Conflicts of Interest}

The authors declare no conflict of interest.

\section{References}

1. Kohan, M.I. Nylon Plastics Handbook; Hanser Publisher: Munich, Germany, 1995.

2. Milbrath, M.O.; Wenger, Y.; Chang, C.W.; Emond, C.; Garabrant, D.; Gillespie, B.W.; Jolliet, O. Apparent half-lives of dioxins, furans, and polychlorinated biphenyls as a function of age, body fat, smoking status, and breast-feeding. Environ. Health Perspect. 2009, 117, 417-425. [CrossRef] [PubMed]

3. Renner, R. Government Watch: In U.S., flame retardants will be voluntarily phased out. Environ. Sci. Technol. 2004, 38, 14A-14A. [CrossRef]

4. Birnbaum, L.S.; Staskal, D.F. Brominated flame retardants: Cause for concern? Environ. Health Perspect. 2004, 112, 9-17. [CrossRef] [PubMed]

5. Liu, Y.; Wang, Q. Preparation of microencapsulated red phosphorus through melamine cyanurate self-assembly and its performance in flame retardant polyamide 6. Polym. Eng. Sci. 2006, 46, 1548-1553. [CrossRef]

6. Fei, G.X.; Liu, Y.; Wang, Q. Synergistic effects of novolac-based char former with magnesium hydroxide in flame retardant polyamide-6. Polym. Degrad. Stabil. 2008, 93, 1351-1356. [CrossRef]

7. Balakrishnan, H.; Hassan, A.; Isitman, N.A.; Kaynak, C. On the use of magnesium hydroxide towards halogen-free flame-retarded polyamide-6/polypropylene blends. Polym. Degrad. Stabil. 2012, 97, 1447-1457. [CrossRef]

8. Dogan, M.; Bayramli, E. Effect of boron-containing materials on the flammability and thermal degradation of polyamide 6 composites containing melamine. J Appl. Polym. Sci. 2010, 118, 2722-2727. [CrossRef]

9. Dasari, A.; Yu, Z.Z.; Mai, Y.W.; Liu, S. Flame retardancy of highly filled polyamide 6/clay nanocomposites. Nanotechnology 2007, 18, 445602-445612. [CrossRef]

10. Nouparvar, H.; Hassan, A.; Mohamad, Z.; Wahit, M.U.; Roozbahani, F. The effect of organoclay contents on morphological characterization, mechanical and thermal properties of epoxidized natural rubber-50 toughened polyamide 6 nanocomposites. J. Polym. Eng. 2014, 34, 59-68. [CrossRef] 
11. Hu, Z.; Chen, L.; Lin, G.P.; Luo, Y.; Wang, Y.Z. Flame retardation of glass-fibre-reinforced polyamide 6 by a novel metal salt of alkylphosphinic acid. Polym. Degrad. Stabil. 2011, 96, 1538-1545. [CrossRef]

12. Zhao, B.; Hu, Z.; Chen, L.; Liu, Y.; Wang, Y.Z. A phosphorus-containing inorganic compound as an effective flame retardant for glass-fiber-reinforced Polyamide 6. J. Appl. Polym. Sci. 2011, 119, 2379-2385. [CrossRef]

13. Chen, J.; Liu, S.; Zhao, J. Synthesis, application and flame retardancy mechanism of a novelflame retardant containing silicon and caged bicyclic phosphate for polyamide 6. Polym. Degrad. Stabil. 2011, 96, 1508-1515. [CrossRef]

14. Ryu, J.; Han, M. Improvement of the mechanical and electrical properties of polyamide 6 nanocomposites by non-covalent functionalization of multi-walled carbon nanotubes. Compos. Sci. Technol. 2014, 102, 169-175. [CrossRef]

15. Wang, M.; Wang, W.; Liu, T.; Zhang, W.D. Melt rheological properties of nylon 6/multi-walled carbon nanotube composites. Compos. Sci. Technol. 2008, 68, 2498-2502. [CrossRef]

16. Meng, H.; Sui, G.X.; Fang, P.F.; Yang, R. Effects of acid- and diamine-modified MWNTs on the mechanical properties and crystallization behavior of Polyamide 6. Polymer 2008, 49, 610-620. [CrossRef]

17. Liang, J.; Xu, Y.; Wei, Z.; Song, P.; Chen, G.; Zhang, W. Mechanical properties, crystallization and melting behavior of carbon fiber-reinforced PA6 composites. J. Therm. Anal. Calorim. 2014, 115, 209-218. [CrossRef]

18. Wang, Z.Y.; Feng, Z.Q.; Liu, Y.; Wang, Q. Flame retarding glass fibers reinforced polyamide 6 by melamine polyphosphate/polyurethane-encapsulated solid acid. J. Appl. Polym. Sci. 2007, 105, 3317-3322. [CrossRef]

19. Liu, Y.; Wang, Q. The investigation on the flame retardancy mechanism of nitrogen flame retardant melamine cyanurate in Polyamide 6. J. Polym. Res. 2009, 16, 583-589. [CrossRef]

20. Isbasar, C.; Hacaloglu, J. Investigation of thermal degradation characteristics of polyamide- 6 containing melamine or melamine cyanurate via direct pyrolysis mass spectrometry. J. Anal. Appl. Pyrol. 2012, 98, 221-230. [CrossRef]

21. Granzow, A. Flame retardation by phosphorus compounds. Accounts Chem. Res. 1978, 11, 177-183. [CrossRef]

22. Levchik, S.V.; Weil, E.D. Combustion and fire retardancy of aliphatic nylons. Polym. Int. 2000, 49, 1033-1073. [CrossRef]

23. Levchik, S.V.; Weil, E.D. A review of recent progress in phosphorus-based flame retardants. J. Fire Sci. 2006, 24, 345-364. [CrossRef]

24. Enescu, D.; Frache, A.; Lavaselli, M.; Monticelli, O.; Marino, F. Novel phosphorous-nitrogen intumescent flame retardant system. Its effects on flame retardancy and thermal properties of polypropylene. Polym. Degrad. Stabil. 2013, 98, 297-305. [CrossRef]

25. Schafer, A.; Seibold, S.; Lohstroh, W.; Walter, O.; Doring, M. Synthesis and properties of flame-retardant epoxy resins based on DOPO and one of its analog, DPPO. J. Appl. Polym. Sci. 2007, 105, 685-696. [CrossRef] 
26. Konig, A.; Kroke, E. Methyl-DOPO-A new flame retardant for flexible polyurethane foam. Polym. Adv. Technol. 2011, 22, 5-13. [CrossRef]

27. Neisius, M.; Liang, S.; Mispreuve, H.; Gaan, S. Phosphoramidate-containing flame retardant flexible polyurethane foams. Ind. Eng. Chem. Res. 2013, 52, 9752-9762. [CrossRef]

28. Buczko, A.; Stelzig, T.; Bommer, L.; Rentsch, D.; Heneczkowskic, M.; Gaan, S. Bridged DOPO derivatives as flame retardants for PA6. Polym. Degrad. Stabil. 2014, 107, 158-165. [CrossRef]

29. Konig, A.; Kroke, E. Flame retardancy working mechanism of methyl-DOPO and MPPP inflexible polyurethane foam. Fire Mater. 2012, 36, 1-15. [CrossRef]

30. Brydson, J.A. Principles of the processing of plastics. In Plastics Materials, 7th ed.; Butterworth-Heinemann: Oxford, UK, 1999; pp. 158-182.

31. American Society for Testing and Materials (ASTM). UOP389-10, Trace Metals in Organics by Wet Ashing-ICP-OES; ASTM: West Conshohocken, PA, US, 2010.

32. American Society for Testing and Materials (ASTM). ASTM D4440-08, Standard Test Method for Plastics: Dynamic Mechanical Properties Melt Rheology; ASTM: West Conshohocken, PA, USA, 2007.

33. American Society for Testing and Materials (ASTM). ISO 179-2:1997, Plastics-Determination of Charpy Impact Properties-Instrumented Impact Test; ASTM: West Conshohocken, PA, USA, 1999.

34. American Society for Testing and Materials (ASTM). ASTM D7309-11, Standard Test Method for Determining Flammability Characteristics of Plastics and Other Solid Materials Using Microscale Combustion Calorimetry; ASTM: West Conshohocken, PA, USA, 2011.

35. American Society for Testing and Materials (ASTM). ASTM D 3801, Tests for Flammability of Plastic Materials for Parts in Devices and Appliances; ASTM: West Conshohocken, PA, USA, 2006.

36. Redfern, J.P. Property evaluation of FR polymeric materials using a range of instrumental techniques. Polym. Degrad. Stabil. 1999, 64, 561-572. [CrossRef]

37. Levchik, S.V.; Weil, E.D.; Lewin, M. Thermal decomposition of aliphatic nylons. Polym. Int. 1999, 48, 532-557. [CrossRef]

38. Ke, C.; Li, J.; Fang, K.; Zhu, Q.; Zhu, J.; Yan, Q. Enhancement of a hyperbranched charring and foaming agent on flame retardancy of polyamide 6. Polym. Adv. Technol. 2011, 22, 2237-2243. [CrossRef]

39. Fang, F.; Li, J.; Ke, C.; Zhu, Q.; Tao, K.; Zhu, J.; Yan, Q. Intumescent flame retardation of melamine-modified montmorillonite on polyamide 6: Enhancement of condence phase and flame retardance. Polym. Eng. Sci. 2011, 51, 377-385. [CrossRef]

40. Dahiya, J.B.; Rathi, S.; Bockhorn, H.; Haußmann, M.; Kandola, B.K. The combined effect of organic phoshphinate/ammonium polyphosphate and pentaerythritol on thermal and fire properties of polyamide 6-clay nanocomposites. Polym. Degrad. Stabil. 2012, 97, 1458-1465. [CrossRef]

41. Braun, U.; Schartel, B. Flame retardancy mechanisms of aluminium phosphinate in combination with melamine cyanurate in glass-fibre-reinforced poly(1,4-butylene terephthalate). Macromol. Mater. Eng. 2008, 293, 206-217. [CrossRef] 
42. Braun, U.; Schartel, B.; Fichera, M.A.; Jaeger, C. Flame retardancy mechanisms of aluminium phosphinate in combination with melamine polyphosphate and zinc borate in glass-fibre reinforced polyamide 6,6. Polym. Degrad. Stabil. 2007, 92, 1528-1545. [CrossRef]

43. Chen, Y.; Wang, Q. Preparation, properties and characterizations of halogen-free nitrogen-phosphorous flame-retarded glass fiber reinforced polyamide 6 composite. Polym. Degrad. Stabil. 2006, 91, 2003-2013. [CrossRef]

44. Qin, H.L.; Su, Q.S.; Zhang, S.M.; Zhao, B.; Yang, M.S. Thermal stability and flammability of polyamide 66/montmorillonite nanocomposites. Polymer 2003, 44, 7533-7538. [CrossRef]

45. Hatakeyama, T.; Quinn, F.X. Thermal Analysis Fundamentals and Applications to Polymer Science, 2nd ed.; Wiley: Chichester, UK, 1999.

46. Perez, R.M.; Sandler, J.K.W.; Altstadt, V.; Hoffmann, T.; Pospiech, D.; Ciesielski, M.; Doring, M.; Braun, U.; Knoll, U.; Schartel, B. Effective halogen-free flame retardants carbon fiber-reinforced epoxy composites. J. Mater. Sci. 2006, 41, 4981-4984. [CrossRef]

47. Murthy, N.H. Hydrogen bonding, mobility, and structural transitions in aliphatic polyamides. J. Polym. Sci. Polym. Phys. 2006, 44, 1763-1782. [CrossRef]

48. Liu, T.; Phang, I.Y.; Shen, L.; Chow, S.Y.; Zhang, W.D. Morphology and mechanical properties of multiwalled carbon nanotubes reinforced nylon-6 composites. Macromolecules 2004, 37, 7214-7222. [CrossRef]

49. Deng, S.H.; Zhou, X.D.; Zhu, M.Q.; Fan, C.J.; Lin, Q.F. Interfacial toughening and consequent improvement in fracture toughness of carbon fiber reinforced epoxy resin composites: Induced by diblock copolymers. Express Polym. Lett. 2013, 11, 925-935. [CrossRef]

50. Gallego, R.; Garcia-Lopez, D.; Lopez-Quintana, S.; Gobernado-Mitre, I.; Merino, J.C.; Pastor, M.J. Toughening of PA6/mEPDM blends by two methods of compounding, extruder and internal mixer: Rheological, morphological and mechanical characterization. Polym. Bull. 2008, 60, 665-675. [CrossRef]

51. Sonnier, R.; Vahabi, H.; Ferry, L.; Lopez-Cuesta, J.M. PCFC: A powerful tool to evaluate the flame retardancy of polymers. In Fire and Polymers VI: New Advances in Flame Retardant Chemistry and Science; Morgan, A., Wilkie, C., Nelson, G., Eds.; American Chemical Society: Washington, DC, USA, 2012; pp. 361-390.

52. Babrauskas, V.; Peacock, R.D. Heat release rate: The single most important variable in fire hazard. Fire Saf. J. 1992, 18, 255-272. [CrossRef]

53. Lyon, R.E.; Walters, R.N. Pyrolysis combustion flow calorimetry. J. Anal. Appl. Pyrol. 2004, 71, 27-46. [CrossRef]

(C) 2015 by the authors; licensee MDPI, Basel, Switzerland. This article is an open access article distributed under the terms and conditions of the Creative Commons Attribution license (http://creativecommons.org/licenses/by/4.0/). 